\title{
Public views on participating in newborn screening using genome sequencing
}

\author{
Yvonne Bombard ${ }^{1,2}$, Fiona A Miller ${ }^{\star, 2}$, Robin Z Hayeems ${ }^{2}$, Carolyn Barg${ }^{2}$, Celine Cressman ${ }^{2}$, June C Carroll ${ }^{3}$, \\ Brenda J Wilson ${ }^{4}$, Julian Little ${ }^{4}$, Denise Avard ${ }^{5}$, Michael Painter-Main ${ }^{6}$, Judith Allanson ${ }^{7,8}$, Yves Giguere ${ }^{9,10}$ \\ and Pranesh Chakraborty 8,11
}

Growing discussion on the use of whole-genome or exome sequencing (WG/ES) in newborn screening (NBS) has raised concerns regarding the generation of incidental information on millions of infants annually. It is unknown whether integrating WG/ES would alter public expectations regarding participation in universal NBS. We assessed public willingness to participate in NBS using WG/ES compared with current NBS. Our secondary objective was to assess the public's beliefs regarding a parental responsibility to participate in WG/ES-based NBS compared with current NBS. We examined self-reported attitudes regarding willingness to participate in NBS using a cross-sectional national survey of Canadian residents recruited through an internet panel, reflective of the Canadian population by age, gender and region. Our results showed that fewer respondents would be willing to participate in NBS using WG/ES compared with NBS using current technologies ( 80 vs $94 \%, P<0.001)$, or perceived a parental responsibility to participate in WG/ES-based NBS vs current NBS (30 vs $48 \%, P<0.001$ ). Our findings suggest that integrating WG/ES into NBS might reduce participation, and challenge the moral authority that NBS programmes rely upon to ensure population benefits. These findings point to the need for caution in the untargeted use of WG/ES in public health contexts.

European Journal of Human Genetics (2014) 22, 1248-1254; doi:10.1038/ejhg.2014.22; published online 19 February 2014

\section{INTRODUCTION}

There is growing discussion of the possibility of using whole-genome or exome sequencing (WG/ES) in newborn screening (NBS) programmes. ${ }^{1,2}$ Advances in technology, coupled with the falling costs of sequencing, have increased enthusiasm about the potential for WG/ES to improve health outcomes. ${ }^{3}$ In the clinical context, small studies suggest the application of WG/ES in guiding the use of targeted therapies or in identifying the genetic causes of neonatal disease. ${ }^{4}$ In the public health context, proof-of-principle studies and targeted funding initiatives have begun to explore how genomic sequencing might augment NBS. ${ }^{2,5}$ However, significant ethical and policy concerns accompany the possibility of incorporating WG/ES into population-wide NBS programmes, where incidental health information of known and unknown clinical significance could be generated on millions of infants annually. Such a major shift in the scope and scale of information generation might alter public expectations regarding participation in universal NBS programmes.

NBS has historically been used to detect specific treatable disorders before the onset of irreversible symptoms. ${ }^{6}$ NBS programmes vary in the number of diseases screened across jurisdiction. Almost all US states screen for 31 'primary' conditions and another 25 for 'secondary' conditions recommended by the American College of Medical Genetics, and endorsed by the Secretary's Advisory
Committee on Heritable Disorders in newborns and children. ${ }^{7,8}$ NBS in the US is largely a compulsory, state-supported activity, justified on the basis of protecting child welfare. ${ }^{1}$ In Canada, NBS programmes screen from 5 to 38 disorders depending on the province or territory. NBS programmes are not mandatory, but parental consent is typically implied rather than explicit, as NBS is considered the standard of care. ${ }^{9}$

While some incidental findings necessarily arise as part of differential clinical diagnosis in current NBS programmes (for example, secondary targets such as non-sickle-cell hemoglobinopathies, and borderline results such as non-classic cystic fibrosis and mild forms of targeted disorders), the introduction of sequencing technologies could dramatically alter the quantity and type of incidental information generated. ${ }^{10}$ First, sequencing can identify all variants in the gene of interest, not only those known to be pathogenic. Thus, a large proportion of identified variants would be of uncertain clinical significance, creating challenges for reporting and follow-up, even with a targeted use of sequencing technologies. Further, when sequencing is used to investigate the entire genome (or exome, if restricted to known coding regions), a host of targets that are secondary or incidental to the testing indication can be identified, including diagnostic information for pediatric conditions (treatable and untreatable), predictive information for adult-onset

${ }^{1}$ Li Ka Shing Knowledge Institute, St. Michael's Hospital, Toronto, Ontario, Canada; ${ }^{2}$ Institute of Health Policy, Management and Evaluation, University of Toronto, Toronto, Ontario, Canada; ${ }^{3}$ Department of Family and Community Medicine, Mount Sinai Hospital, University of Toronto, Toronto, Ontario, Canada; ${ }^{4}$ Department of Epidemiology and Community Medicine, University of Ottawa, Toronto, Ontario, Canada; ${ }^{5}$ Centre for Genomics and Policy, Department of Human Genetics, McGill University, Montreal, Quebec, Canada; ${ }^{6}$ Department of Political Science, University of Toronto, Toronto, Ontario, Canada; 7 Department of Genetics, Children's Hospital of Eastern Ontario, Ottawa, Ontario, Canada; ${ }^{8}$ Department of Pediatrics, University of Ottawa, Ottawa, Ontario, Canada; ${ }^{9}$ Quebec Blood Newborn Screening Program, Department of Medical Biology, CHU de Quebec, Charlesbourg, Quebec, Canada; ${ }^{10}$ Department of Molecular Biology, Medical Biochemistry and Pathology, University of Laval, Quebec, Quebec, Canada; ${ }^{11}$ Newborn Screening Ontario, Children's Hospital of Eastern Ontario, Ottawa, Ontario, Canada

*Correspondence: Dr FA Miller, Institute of Health Policy, Management and Evaluation, 155 College Street, 4th Floor, Toronto, Ontario, Canada M5T 3M6. Tel: +41 6978 3703; Fax: +41 6978 7350; E-mail: fiona.miller@utoronto.ca

Received 27 August 2013; revised 17 January 2014; accepted 22 January 2014; published online 19 February 2014 
disorders (treatable and untreatable), and carrier status. Already, guidance from some professional associations suggests that a minimum list of secondary targets should be searched for and reported when sequencing is conducted clinically, including for adult-onset disorders in children. ${ }^{11}$ Although such guidance is not specific to public health contexts, and is contested, ${ }^{12-15}$ recent experience with targeted multiplex testing ${ }^{7}$ applied to NBS shows that the potential to identify more conditions has sometimes led to a change in screening criteria and difficulty in restricting the reporting of incidental findings when these could be reliably generated. ${ }^{16-18}$

The growing discussion of integrating WG/ES into NBS and recent ACMG clinical recommendations to seek and report incidental findings generated from WG/ES raise anew, and with urgency, questions about the limits of screening and the moral authority of NBS. As a population screening programme offering demonstrable, life-saving clinical benefits to affected infants, ${ }^{6}$ public support is critical for achieving the clinical benefits that NBS programmes seek for the population. Historically, NBS programmes have enjoyed high levels of public and parental support ${ }^{19-21}$ and participation. ${ }^{22,23}$ The unrestricted use of WG/ES might challenge the support upon which these programmes rely, as the scope and scale of incidental health information generated could shift the balance of clinical benefits and harms as well as the presumed obligation of parents to participate. Engaging the public and eliciting social (rather than patient or consumer) values is also critical from a health policy perspective, as these are publicly funded programmes acting in the public's interest on behalf of the health of all children. It is thus important to investigate whether integrating WG/ES would alter public expectations regarding parental participation in NBS, where these judgments are made both by current parents of newborn infants, as well as about and on behalf of all such parents.

To this end, we surveyed a national sample of Canadians to identify willingness to participate in NBS where the use of genome sequencing would identify a host of incidental results, as well their beliefs about parental responsibility to participate in such programmes. As a comparison, we assessed willingness to participate in current NBS programmes that screen for specific, treatable conditions. We postulated that the anticipated participation rate in NBS using genome sequencing would be lower than that in current targeted NBS. Our secondary objective was to assess public beliefs regarding a parental responsibility to participate in NBS, for current targeted NBS, or using WG/ES, which generates incidental results. We expected that a smaller proportion of the public would identify a parental responsibility to participate in NBS using genome sequencing compared with a targeted programme using current technologies. Finally, we aimed to examine the factors associated with a reduced participation in NBS using untargeted genome sequencing, if a reduction in participation was found.

\section{MATERIALS AND METHODS}

\section{Sample and data collection}

In January 2013, we administered a bilingual survey to a sample of Canadians through an internet panel provided by Survey Sampling International (SSI), which hosts online panels to support market and academic research. Eligible panelists were sent an e-mail inviting them to participate in the survey by accessing a link to the survey page. Those willing to participate who met targets for a demographically diverse sample, reflective of the Canadian population by age, gender and region of residence, consistent with 2011 statistics Canada data, ${ }^{24}$ were eligible to complete the questionnaire. To recognize the time invested, SSI provided an incentive to panelists who completed one or more of the three sections of the questionnaire (respondents were able to select reward points, prize draws or cash).

\section{Questionnaire design}

Our questionnaire included items to build and assess knowledge and to measure selected attitudes and demographics. The questionnaire included background information on the principles of screening and the varied effects of NBS (for example, early diagnosis and treatment, reproductive-risk information, false-positive results and overdiagnosis) followed by quizzes, a discrete choice experiment and a reasoning exercise. The questionnaire was developed by a multidisciplinary team on the basis of our preceding qualitative studies $^{19,25}$ and a review of the literature, ${ }^{26-31}$ and was pretested through face-to-face cognitive interviews (over three rounds with $n=16$ ) and piloted with members of the internet panel $(n=87)$ to assess comprehension, face and content validity.

We took several steps to ensure our respondent population was informed about NBS and as engaged in the survey as possible. First, true or false questions were incorporated throughout the background portion of the survey to verify respondents' understanding of key concepts (section 1 covered: early diagnosis and treatment, reproductive-risk information, false-positive results and overdiagnosis). Second, professionally designed images were used to help convey the process of NBS in a visually appealing way. Third, the survey was split into three separate sections; respondents were given the option to continue after each section, with incentives dependent on the section(s) completed. Following survey administration, we removed respondents who sped (that is, completed the survey below minimum times per section) or 'straight-lined' (that is, providing answers to blocked items along only one column) through the survey to ensure data quality.

For the items that are the focus of this paper (section 2 of the survey), we provided background on the current screening technologies used in NBS and on WG/ES. We described current technologies as identifying 'specific, rare childhood diseases', whereas genome sequencing would identify 'information about many diseases at once - not specific ones'. We suggested sequencing would 'identify rare, serious childhood diseases if present and would also generate large amounts of extra information about the baby's chances of getting all sorts of other diseases, now or in the future' (Supplementary Appendix 1).

\section{Measures}

Willingness to participate in NBS. We asked respondents to indicate their willingness to participate in targeted NBS using current technologies and untargeted NBS using WG/ES. Respondents were asked to choose 'yes' or 'no' to the following question for each technology: 'As a parent, would you choose to participate in this type of newborn screening program?'

Parental responsibility to participate in NBS. We asked respondents about their views on parental responsibility to participate in targeted NBS using current technologies and untargeted WG/ES. We adapted a measure of personal responsibility to participate in screening from the cancer context, ${ }^{28}$ focusing on parental responsibility, which is appropriate to the infant screening setting. Respondents were asked to choose 'yes' or 'no' to the following question for each technology: 'Would you consider other parents irresponsible if they refused to participate in this type of newborn screening program?'

Attitudes towards science, technology, health care and understanding of NBS. We assessed attitudes towards science, technology and health care based on modified items from the literature $e^{28,29,31}$ and their understanding of NBS using newly developed items (Table 2). Individuals reported their prior awareness of NBS. Respondents reviewed our educational intervention describing screening versus diagnostic follow-up of screen-positive infants. We also provided an overview of the varied effects of NBS, including those impacting affected infants and their families (early diagnosis and treatment, reproductive-risk information) and those imposed on the rest of the population (false-positive results, overdiagnosis). We assessed respondents' understanding of NBS and its varied effects from responses to our educational quizzes; these questions comprised our 'understanding of NBS' educational intervention and subsequent index (described below). Finally, half of the respondents were randomly assigned to a reasoning exercise that elicited value-based reasons for pursuing NBS (for example, medical benefits, early knowledge, reproductive-risk 
information; results reported elsewhere); these individuals comprised our 'exposed to reasoning' group.

Data analysis. We used descriptive and multivariate statistics, using $\chi^{2}$-tests to assess proportional differences; one-sided $P$-values of $<0.05$ indicated statistical significance. We produced two composite measures: an 'understanding of NBS' index and a 'confidence in science' index. Correct responses to the educational quizzes were summed to produce an 'understanding of NBS' index, scored from 8 to 21 , with higher scores indicating greater understanding of NBS and its effects. The 'confidence in science' index was created on the basis of selected items from the Eurobarometer's Social Values on Science and Technology Survey, ${ }^{31}$ scored on a scale of $0-1$ indicating less or more confidence in science, respectively (comprising items listed under 'attitudes towards science' in Table 2). Reliability analyses were conducted on these scalar items to create indices for inclusion in our regression models with Cronbach's alpha $\geq 0.60 .^{32}$ We conducted two separate logistic regressions to examine factors associated with reduced participation in NBS using untargeted genome sequencing. The first logistic regression model examined factors associated with the reduced willingness to participate in NBS using WG/ES, and included only those respondents who would be willing to participate in current NBS programmes. The second logistic regression model examined factors associated with reduced perceptions of a parental responsibility to participate in NBS using WG/ES, and included only those respondents who believed that parents have a responsibility to participate in targeted NBS using current technologies. Independent variables were entered into the models at the same time. We ran post-test estimations of the average marginal effects (AME) and then multiplied all the AMEs by 100 to generate percentage probabilities. We utilized AME as a means of presenting the results in a clear and encompassing manner and as a means to avoid over/underestimating the conditional effects of our dependent variable, which is a potential drawback of odds ratios. ${ }^{33}$ Our particular models are amendable to AME as the dependent variable (that is, expected participation rates in NBS) is skewed towards an unwillingness to participate or others not having a responsibility to participate in WG/ES-based NBS. Data were managed and analysed using Stata (version 10.1, StataCorp LP., Station College, TX, USA).

\section{RESULTS}

\section{Survey respondents}

Response rates are not typically measured in internet surveys, where recruitment is designed to achieve quotas. ${ }^{34}$ The survey participation rate was $94 \%$ (2345/2499; ratio of unique visitors who agreed to participate/unique first survey page visitors); of these, 1213 completed responses met quality criteria for a $52 \%$ completion rate (ratio of respondents who finished section 2-those excluded for quality reasons/agreed to participate). By design, our sample was demographically diverse and reflective of the Canadian population by age, gender, and region. However, our sample is better educated and appears to earn more than the general population ${ }^{26,35}$ (Table 1).

While comparing respondents who completed sections 1 and 2 $(n=1213)$ with those who completed only section $1(n=669)$, those who continued were more likely to be women $(P<0.001)$, to be older $(P<0.01)$ and to score better on the NBS understanding questions $(P<0.01)$. There was no difference between groups on whether or not they had children or whether or not they had a family history of genetic disease.

\section{Willingness to participate in NBS using genome sequencing} A smaller proportion would be willing to participate in NBS using untargeted genome sequencing compared with targeted NBS using current technologies $(n=965(80 \%)$ vs $n=1145$ (94\%), $P<0.001$ (Figure 1)).
Table 1 Socio-demographic characteristics

Total $(\mathrm{n}=1213)$

$\mathrm{n}$

$\%$

\begin{tabular}{lll}
\hline $\begin{array}{l}\text { Sex } \\
\text { Female }\end{array}$ & \\
Male & 584 & 48 \\
& 629 & 52 \\
Age group & & \\
$18-35$ & & 31 \\
$36-54$ & 372 & 40 \\
$55+$ & 486 & 29
\end{tabular}

$\begin{array}{lrc}\text { Geographical region } & & \\ \text { Atlantic Canada } & 90 & 7 \\ \text { Quebec } & 282 & 23 \\ \text { Ontario } & 454 & 37 \\ \text { Western Canada } & 387 & 32\end{array}$

Children $(\mathrm{n}=1213)$

None

413

34

At least one

800

Family history of genetic disease $(\mathrm{n}=1146)$

Yes

211

18

No

935

82

Marital status

Single/separated/divorced/widowed 470

Married/common law

743

39

61

Education ( $\mathrm{n}=1201)$

High school or less

$391 \quad 32$

Other post-secondarya

35

Some post-secondary or more

384

32

Household income $(\mathrm{n}=1125)$

Less than $\$ 40000$

$\$ 40000$ to $\$ 79999$

392

415

$\$ 80000$ or more

318

35

37

28

an Canada this refers to college or CEGEP in Quebec.

\section{Parental responsibility to participate in NBS using genome sequencing}

A smaller proportion perceived a parental responsibility to participate in NBS using untargeted genome sequencing compared with targeted NBS using current technologies $(n=367$ (30\%) vs $n=585$ (48\%), $P<0.001$ (Figure 1)).

\section{Attitudes towards science, technology, health care and NBS}

Respondents expressed enthusiasm towards science and technology. A majority (89\%) felt it was important to gain access to the most advanced technologies (Table 2). There was high confidence in science (mean $=0.80, \mathrm{SD}=0.16)$ with the majorities valuing $(83-87 \%)$ and trusting $(81 \%)$ medical research. Majorities also preferred the use of scientific evidence $(82 \%)$ and expert advice $(74 \%)$ in making health care decisions. However, only half indicated a trust in the quality of health care (53\%) and $41 \%$ felt that access to modern medicine could lead to medical cures. Although the majority were unfamiliar with NBS (61\%), they exhibited high understanding of NBS once exposed 


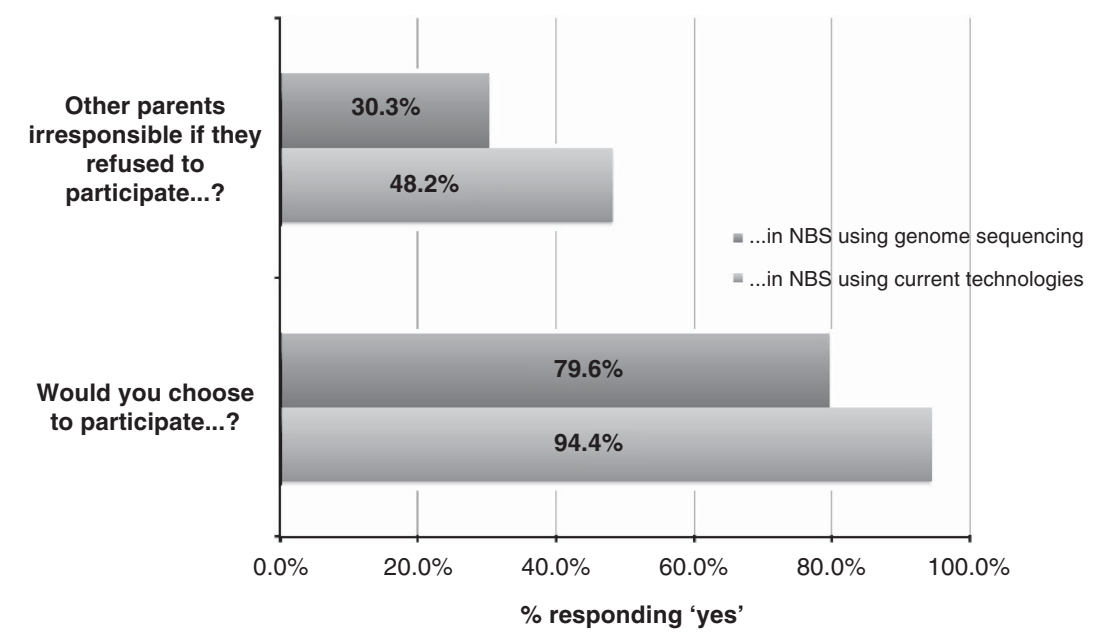

Figure 1 Public willingness and parental responsibility to participate in NBS using current technologies vs untargeted genomic sequencing. NBS, newborn screening.

to our educational intervention (average of 19 correct responses out of 21 questions; Table 2).

\section{Factors associated with reduced participation in NBS using genome} sequencing

Among those willing to participate in targeted NBS using current technologies ( $n=918$ without missing data), women, on an average, were $7 \%$ more likely than men to decline participation in NBS using WG/ES. Those with increased understanding of NBS and its effects (assessed through our educational intervention) were 4\% more likely to refuse to participate in NBS using WG/ES. Those with less confidence in science were, on average, $30 \%$ more likely to decline participating in NBS using WG/ES compared with those most confident in science. Similar findings were found with respect to trust in the quality of health care and the use of scientific evidence in health care (Table 3).

Factors associated with reduced parental responsibility to participate in NBS using genome sequencing

Among those who believe that parents have a responsibility to participate in targeted NBS using current technologies $(n=472$ without missing data), respondents with an increased understanding about NBS and its effects were, on average, almost 5\% less likely to believe that parents have a responsibility to participate in untargeted NBS using WG/ES. Compared with those previously unaware of NBS, respondents reporting more awareness of NBS were typically between 14 and $32 \%$ less likely to believe that parents have a responsibility to participate in untargeted NBS using WG/ES. Further, those sceptical of science were $\sim 58 \%$ less likely to expect parents to participate in untargeted NBS using WG/ES. Those earning more than $\$ 80000$ were between 11 and $12 \%$ less likely to believe parents should participate compared with those earning lower wages (Table 4).

\section{DISCUSSION}

Amid growing interest in the role of WG/ES in NBS, ${ }^{1,2}$ our study provides timely insight into its potential impact on public expectations regarding participation in NBS. Similar to previous reports, we found that a large majority of the public is committed to participating in current NBS programmes that identify known and treatable disorders. ${ }^{19-21}$ However, the public's willingness to participate in NBS was reduced for untargeted WG/ES compared with targeted NBS using current technologies, as was the perception of a parental responsibility to participate. Our results suggest that integrating WG/ES into NBS in an untargeted manner might reduce public participation in NBS and challenge the moral authority that NBS programmes rely upon to ensure population benefits.

The reduction in expected participation and perceived parental responsibility was driven by scepticism towards science as well as an understanding of NBS and its effects. These findings are striking given the enthusiasm for science and technology among our respondents, the general public's enthusiasm for screening ${ }^{28}$ and their tendency to 'buy into' the messages emanating from scientists, media and commercial interests 'hyping' the promises of science and genomics. ${ }^{36}$ Indeed, such enthusiasm was demonstrated in a recent study that reported parental interest in WG/ES-based NBS, based on the perception that WG/ES-based screening would be more accurate. ${ }^{37}$

There are many potential explanations for our findings. It is possible that the sensationalized rhetoric around science and genomics has promulgated both enthusiasm and healthy scepticism of its limits and applications for health care and screening. It is also possible that the heightened discourse emerging about the potential harms of cancer screening ${ }^{38,39}$ has moderated the enthusiasm towards screening generally. Indeed, those who understood the varied effects of NBS were less willing, and felt less of a parental responsibility, to participate in NBS using new genomic technologies. Respondents in our survey perceived a relatively low level of parental responsibility to participate in either form of NBS (30-47\%), likely a function of the discrete choice experiment and reasoning exercises they underwent, which required their deep engagement with the risks and benefits of NBS. This hypothesis is supported by previous studies that demonstrate that informing potential participants about the harms of screening may reduce participation rates, as was the case in our study. ${ }^{40}$ Our study begins to explain how attitudes towards science might influence public expectations about participation in infant screening programmes that adopt new genomic technologies, as well as parental obligations towards participation in such programmes.

Our data should be interpreted in light of several potential limitations. Although our completion rate was very good - 94\% among contacted panel respondents and 52\% after applying typical quality criteria - systematic bias between respondents and nonrespondents is possible. These concerns are reduced by the fact that our sample was demographically diverse and reflective of the 
Table 2 Attitudes towards science, technology, health care and understanding of newborn screening

Total $(\mathrm{n}=1213)$

n $\%$

Attitudes towards technology

Modern medicine can cure almost any illness for people who have access to the most advanced technology \& treatment

$\begin{array}{lll}\text { Agree }^{a} & 494 & 40.7 \\ \text { Neutral }^{\text {Disagree }} & 299 & 24.7 \\ \text { D }^{b} & 420 & 34.6\end{array}$

Importance in accessing the most advanced tests, drugs, medical procedures and equipment

Absolutely essential/very important $\quad 1075 \quad 88.6$

Not at all important/somewhat important

$138 \quad 11.4$

Trust in health care

The government will ensure a high quality health care system

Agree $^{a}$

$639 \quad 52.7$

Neutral

$393 \quad 32.4$

Disagree $^{\mathrm{b}}$

$181 \quad 14.9$

Governance of heath care ${ }^{\mathrm{d}}$

Decision on health care programmes should be based primarily..

$\begin{array}{lll}\text {.... on the advice of experts } & 902 & 74.4\end{array}$

...on scientific evidence about risks involved $\quad 990 \quad 81.6$

Attitude toward science $(\mathrm{n}=1102)$

Medical research will help to cure illnesses such as AIDS, cancer

Strongly disagree

$7 \quad 0.6$

Disagree

$20 \quad 1.8$

Neutral

11910.8

Agree

$431 \quad 39.1$

Strongly agree

$525 \quad 47.6$

Most medical researchers want to work on things that will make life better for the average person

$\begin{array}{lll}\text { Strongly disagree } & 12 & 1.1\end{array}$

$\begin{array}{lrr}\text { Disagree } & 29 & 2.6\end{array}$

Neutral $\quad 14313.0$

$\begin{array}{lll}\text { Agree } & 495 & 44.9\end{array}$

$\begin{array}{lll}\text { Strongly agree } & 423 & 38.4\end{array}$

The privacy and confidentiality of people who participate in medical research will be protected

$\begin{array}{lrc}\text { Strongly disagree } & 11 & 1.0 \\ \text { Disagree } & 24 & 2.2 \\ \text { Neutral } & 176 & 16.0 \\ \text { Agree } & 462 & 41.9 \\ \text { Strongly agree } & 429 & 38.9\end{array}$

Awareness of NBS

How much did you know about NBS before today?

Never heard of it

$362 \quad 29.8$

$\begin{array}{lll}\text { Heard of it but knew nothing about it } & 377 & 31.1\end{array}$

Knew a little about it $\quad 424 \quad 35.0$

Knew a lot about it

Understanding of NBS and its effects

$50 \quad 4.1$

Index of NBS understanding ${ }^{f}$

Mean (SD)

$18.9(2.2)$

aRespondents checking 'strongly agree' and 'agree' to these questions were included in this category.

'Respondents checking 'strongly disagree' and 'disagree' to these questions were included in this category.

'Selected item from a public trust in health care survey. ${ }^{29}$

dSelected items from the Eurobarometer's Social Values on Science and Technology Survey. ${ }^{31}$

Respondents were able to select one response from these two options.

eSelected items from the Eurobarometer's Social Values on Science and Technology Survey. ${ }^{3}$

'Confidence in science' index created (alpha $=0.70 ; 0-1$ scale, mean $=0.80, S D=0.16$ ).

${ }^{f}$ Index sums together the number of correct responses given to 21 questions (alpha $=0.67$ ).
Table 3 Factors associated with reduced participation in NBS using genome sequencing among willing participants of targeted NBS using current technologies (logistic regression)

Unwilling to

Participate in NBS

using WG/ES

Demographics

Age (reference: $55+$ )

18-35 -4.6 (3.3)

36-54 $-0.9(2.9)$

$-0.9(2.9)$
$7.1(2.5)^{*}$

Education (reference: post-secondary)

High school or less

$-3.0(3.4)$

College/CEGEP

$1.4(3.0)$

Income (reference: $\$ 80000+$ )

Less than $\$ 40000$

$1.1(3.5)$

$\$ 40000-\$ 79999$

$-0.8(3.1)$

$-3.7(2.8)$

$-5.2(3.3)$

Family history of disease

$3.7(.2 .9)$

Enthusiasm towards science and technology

Confidence in science ${ }^{b} \quad-30.6(8.6)^{* * *}$

Modern medicine can cure all (reference: disagree)

Neutral

$-3.9(3.3)$

Agree

$2.1(2.8)$

Importance in accessing most advanced procedures

$-5.6(3.6)$

Trust in health care

The government will ensure a high quality health care system (reference: disagree)

Neutral

$-2.3(3.3)$

Agree

$-7.9(3.3)^{*}$

Governance of heath care

Decision on health care programmes should be left to experts $\quad-1.8$ (2.8) Decisions on health care programmes should be based on $\quad-9.6(2.9)^{* * *}$

scientific evidence about risks involved

Understanding of NBS \& its effects ${ }^{\mathrm{d}}$

Awareness of NBS (reference: never heard about it)

Heard of it, but know nothing about it

$1.8(3.3)$

Heard a little about it

$2.1(3.3)$

Heard a lot about it

$-1.3(6.6)$

Index of NBS understanding

$4.0(0.8)^{* * *}$ $\mathrm{N}$

918

Abbreviations: NBS, newborn screening; WG/ES, whole genome/exome sequencing.

Cell entries are average marginal effects (probabilities) translated into percentages with s.e.'s in parentheses. ${ }^{*} P<0.05 ; * * P<0.01 ; * * * P<0.001$

Pseudo $R^{2}=0.13$, Likelihood ratio test $(\operatorname{LR}(10)=112.33 ; P<0.001)$

aDependent variable $=$ unwillingness to participate in NBS using WG/ES

belected items from the Eurobarometer's Social Values on Science and Technology Survey. ${ }^{31}$

'Confidence in science' index created (Alpha $=0.70 ; 0-1$ scale, mean $=0.80, \mathrm{SD}=0.16$ ).

'Selected item from a public trust in health care survey. ${ }^{29}$

dExposure to reasoning exercise included in model, but omitted from table (insignificant

relationship).

eIndex sums together the number of correct responses given to 21 questions (alpha $=0.67$ ).

Canadian population by age, gender and region, and comprised an engaged group who completed our survey despite several opportunities to end the questionnaire early, and as demonstrated by the higher understanding scores of those who completed section 2 of the survey compared with those who only completed section 1. Further, our completion rate is typical of internet surveys that target samples representing the population on key demographic criteria. ${ }^{26,41,42,43}$ Although individuals who earn less and have less formal education were under-represented, bivariate analyses demonstrated that the attitudes and beliefs examined did not differ significantly along 
Table 4 Factors associated with reduced parental responsibility to participate in NBS using genome sequencing among respondents who perceive a parental responsibility to participate targeted NBS using current technologies (logistic regression)

Parents do not have a

responsibility to participate in

NBS using WG/ESa

$\begin{array}{lr}\text { Demographics } & \\ \text { Age (Reference: } 55+\text { ) } & \\ \text { 18-35 } & 0.4(6.0) \\ \text { 36-54 } & -6.4(5.1) \\ \text { Female } & 3.4(4.5) \\ \text { Education (Reference: post-secondary) } & \\ \quad \text { High school or less } & -3.9(5.6) \\ \quad \text { College/CEGEP } & -1.4(5.3) \\ \text { Income (Reference: } \$ 80000+\text { ) } & \\ \quad \text { Less than } \$ 40000 & -10.8(6.2) \\ \quad \$ 40000-\$ 79999 & -11.9(5.4)^{*} \\ \text { Married/common law } & -4.3(4.9) \\ \text { Family history of disease } & -1.9(5.5) \\ \text { Children } & -4.9(5.1)\end{array}$

Enthusiasm towards science and technology

Confidence in science

Modern medicine can cure all (reference: disagree)

Neutral

$-58.0(15.9)^{* * *}$

Agree

$-3.5(5.8)$

$-6.2(5.0)$

Importance in accessing most advanced procedures

Trust in health care

The government will ensure a high quality health care system (reference: disagree)

Neutral $6.1(7.0)$

Agree

$-4.8(6.4)$

Governance of heath care

Decision on health care programmes should be left

$-0.8(5.6)$

to experts

Decisions on health care programmes should be

based on scientific evidence about risks involved

Understanding of NBS and its effects ${ }^{\mathrm{d}}$

Awareness of NBS (reference: never heard about it)

Heard of it, but know nothing about it

Heard a little about it

Heard a lot about it

Index of NBS understanding

\section{$14.3(5.7)^{*}$ \\ $17.3(5.7)^{* *}$ \\ $32.2(11.1)^{* *}$ \\ $4.8(1.0)^{* * *}$ \\ 472}

Abbreviations: NBS, newborn screening: WG/ES, whole genome/exome sequencing.

Cell entries are average marginal effects (probabilities) translated into percentages with

standard errors in parentheses. ${ }^{*} P<0.05 ;{ }^{* *} P<0.01 ;{ }^{* *} P<0.001$

Pseudo $R^{2}=0.14$, likelihood ratio test $(\operatorname{LR}(10)=92.75 ; P<0.001)$.

a Dependent variable $=$ Belief that parents do not have a responsibility to participate in NBS using WG/ES.

b'Confidence in science' index created based on selected items from the Eurobarometer's Social Values on Science and Technology Survey. ${ }^{31}$ (alpha $=0.70 ; 0-1$ scale, mean $=0.80$, SD $=0.16)$

'Selected item from a public trust in health care survey. ${ }^{29}$

dExposure to reasoning exercise included in model, but omitted from table (insignificant

relationship).

eIndex sums together the number of correct responses given to 21 questions (alpha $=0.67$ ).

these characteristics (data not shown). Further, our findings on the predictors of reduced obligations to participate in WG/ES-based NBS were based on a smaller sub-sample of 472 and should be interpreted cautiously. Our findings are also limited because we assessed hypothetical participation, which may not accurately predict actual uptake. $^{44-46}$ For this reason we focused our analyses on the relative differences between expected participation and a responsibility to participate. Further, the intent of the study was not to predict

behaviour but to assess public expectations about participation, or a responsibility to participate, in WG/ES-based NBS programmes.

Our study suggests that the public's willingness to participate in NBS might be negatively impacted by integrating WG/ES in an untargeted manner, as would expectations of a parental responsibility to participate. These findings highlight the need for caution in the uptake of untargeted technological advances within NBS programmes, to ensure the preservation of the public health goals and moral authority that such initiatives rely upon to produce population-wide benefits. Given the public support of current NBS programmes that identify targeted conditions, it is possible that the public would be supportive of NBS using targeted WG/ES approaches. However, further research would be warranted to explore public expectations of participating in NBS using targeted WG/ES that limit the generation of incidental health information of known and unknown clinical significance. Finally, it is unknown how generalizable these findings are to other countries given the influence of public values towards science, technology and health care, which are known to differ across jurisdiction. ${ }^{29-31}$ Additional public engagement research would be valuable to inform evolving NBS policy and could determine variations in public expectations and participation in WG/ES-based NBS across jurisdictions.

\section{CONFLICT OF INTEREST}

The authors declare no conflict of interest.

\section{ACKNOWLEDGEMENTS}

We thank the study participants for the time and insight they provided for our survey. Research for this project was supported by the Canadian Institutes of Health Research. YB was supported by a fellowship from the Canadian Institutes of Health Research. YG is a senior research scholar from the FRQ-S (Fonds de Recherche du Quebec-Sante).

1 Goldenberg AJ, Sharp RR: The ethical hazards and programmatic challenges of genomic newborn screening. JAMA 2012; 307: 461-462.

2 National Institute of Child Health and Human Development. Newborn screening in the genomic era: setting a research agenda. 2011. http://www.nichd.nih.gov/about/ meetings/2010/121410.cfm (accessed 26 March 2013).

3 Bombard Y, Bach P, Offit K: Translating genomics in cancer care. J Natl Compr Canc Netw 2013; 11: 1343-1353.

4 Saunders CJ, Miller NA, Soden SE et al: Rapid whole-genome sequencing for genetic disease diagnosis in neonatal intensive care units. Sci Trans/ Med 2012; 4: 154 ra135.

5 Solomon B, Pineda-Alvarez D, Bear K, Mullikin J, Evans J: Applying genomic analysis to newborn screening. Mol Syndromol 2012; 3: 59-67.

6 Kuehn BM: After 50 years, newborn screening continues to yield public health gains. JAMA 2013; 309: 1215-1217.

7 Watson MS, Lloyd-Puryear MA, Mann MY, Rinaldo P, Howell RR: Newborn screening: toward a uniform screening panel and system. Genet Med 2006; 8: 12S-252S.

8 Kemper AR, Green NS, Calonge N et al: Decision-making process for conditions nominated to the recommended uniform screening panel: statement of the US Department of Health and Human Services Secretary/'s advisory committee on heritable disorders in newborns and children. Genet Med 2014; 16: 183-187.

9 Morrison A, Dowler J: Newborn Screening for Disorders and Abnormalities in Canada. Ottawa: Canadian Agency for Drugs and Technologies in Health, 2011.

10 Cassa CA, Savage SK, Taylor PL, Green RC, McGuire AL, Mandl KD: Disclosing pathogenic genetic variants to research participants: quantifying an emerging ethical responsibility. Genome Res. 2012; 22: 421-428.

11 Green RC, Berg JS, Grody WW et al: ACMG recommendations for reporting of incidental findings in clinical exome and genome sequencing. Genet Med 2013; 15: 565-574.

12 Allyse M, Michie M: Not-so-incidental findings: the ACMG recommendations on the reporting of incidental findings in clinical whole genome and whole exome sequencing. Trends Biotechnol 2013; 31: 439-441.

13 Wolf SM, Annas GJ, Elias S: Point-counterpoint patient autonomy and incidental findings in clinical genomics. Science 2013; 340: 1049-1050.

14 van EI CG, Cornel MC, Borry P et al: Whole-genome sequencing in health care. Eur J Hum Genet 2013; 21: 580-584.

15 PHG Foundation. American College of Medical Genetics and Genomics Recommendations. Cambridge, UK: Public Health Genomics Foundation, 2013. 
16 Miller FA, Robert JS, Hayeems RZ: Questioning the consensus: managing carrier status results generated by newborn screening. Am J Public Health 2009; 99: 210.

17 Bombard Y, Miller FA, Hayeems RZ, Avard D, Knoppers BM: Reconsidering reproductive benefit through newborn screening: a systematic review of guidelines on preconception, prenatal and newborn screening. Eur J Hum Genet 2010; 18 751-760.

18 Bombard Y, Grob R, Schlesinger M: Genome sequencing in newborn screening: incidental findings, policy legacies and the imperative for improved governance. (Submitted).

19 Hayeems RZ, Miller FA, Bombard Y et al: Expectations and values about expanded newborn screening: a public engagement study. Health Expect 2014; 16: 183-187.

20 Mak CM, Lam CW, Law CY et al: Parental attitudes on expanded newborn screening in Hong Kong. Public Health 2012; 126: 954-959.

21 Etchegary H, Dicks E, Hodgkinson K, Pullman D, Green J, Parfey P: Public attitudes about genetic testing in the newborn period. J Obstet Gynecol Neonatal Nurs 2012; 41: 191-200.

22 Liebl B, Nennstiel-Ratzel U, von Kries R et al: Very high compliance in an expanded MS-MS-based newborn screening program despite written parental consent. Prev Med 2002; 34: 5 .

23 Dhondt J-L: Implementation of informed consent for a cystic fibrosis newborn screening program in France: low refusal rates for optional testing. J Pediatr 2005, 147: S106-S108.

24 Census of Population, 2010. http://www12.statcan.gc.ca/census-recensement/2011/ rt-td/index-eng.cfm\#tab5 (accessed 21 March 2013).

25 Bombard Y, Miller FA, Hayeems RZ et al: Citizens' values regarding research with stored samples from newborn screening in Canada. Pediatrics 2012; 129: 239-247.

26 Johri M, Damschroder LJ, Zikmund-Fisher BJ, Kim SY, Ubel PA: Can a moral reasoning exercise improve response quality to surveys of healthcare priorities? J Med Ethics 2009; 35: 57-64.

27 Willison DJ, Swinton M, Schwartz $L$ et al: Alternatives to project-specific consent for access to personal information for health research: insights from a public dialogue. BMC Med Ethics 2008; 9: 18.

28 Schwartz LM, Woloshin S, Fowler Jr FJ, Welch HG: Enthusiasm for cancer screening in the United States. JAMA 2004; 291: 71-78.

29 Straten GF, Friele RD, Groenewegen PP: Public trust in Dutch health care. Soc Sci Med 2002; 55: 227-234.

$30 \mathrm{Kim} \mathrm{M}$, Blendon RJ, Benson JM: How interested are Americans in new medical technologies? A multicountry comparison. Health Aff (Millwood) 2001; 20: 194-201.
31 Gaskell G, Allansdottir A, Allum N et al: The 2010 Eurobarometer on the life sciences. Nat Biotechnol 2011; 29: 113-114.

32 Nunnally J: Psychometric Theory, 2nd edn. New York: McGraw-Hill, 1979.

33 Katz KA: The (relative) risks of using odds ratios. Arch Dermatol 2006; 142 761-764.

34 Eysenbach G: Improving the quality of web surveys: the checklist for reporting results of internet e-surveys (CHERRIES). J Med Internet Res 2004; 6: e34.

35 Census of Population, 2006. http://www12.statcan.gc.ca/census-recensement/2011/ rt-td/index-eng.cfm\#tab5 (accessed 21 March 2013).

36 Caulfield T, Condit C: Science and the sources of hype. Public Health Genomics 2012; 15: 209-217.

37 Goldenberg AJ, Dodson DS, Davis MM, Tarini BA: Parents' interest in whole-genome sequencing of newborns. Genet Med 2013; 16: 78-84.

38 Jorgensen KJ, Gotzsche PC: Overdiagnosis in publicly organised mammography screening programmes: systematic review of incidence trends. Br Med J 2009; 339: b2587.

39 Bach PB, Mirkin JN, Oliver TK et al: Benefits and harms of CT screening for lung cancer: a systematic review. JAMA 2012; 307: 2418-2429.

40 Perneger TV, Cullati S, Schiesari L, Charvet-Berard A: Impact of information about risks and benefits of cancer screening on intended participation. Eur J Cancer 2010; 46: 2267-2274.

41 Schlesinger M, Kanouse DE, Rybowski L, Martino SC, Shaller D: Consumer response to patient experience measures in complex information environments. Med Care 2012 50: S56-S64.

42 Miller FA, Mentzakis E, Axler R et al: Do Canadian researchers and the lay public prioritize biomedical research outcomes equally? a choice experiment. Acad Med 2013; 88: 519-526.

43 Stewart RJ, Caird J, Oliver K, Oliver S: Patients' and clinicians' research priorities. Health Expect 2011; 14: 439-448.

44 Johnsson L, Helgesson G, Rafnar $T$ et al: Hypothetical and factual willingness to participate in biobank research. Eur J Hum Genet 2010; 18: 1261-1264.

45 Sawyer SM, Cerritelli B, Carter LS, Cooke M, Glazner JA, Massie J: Changing their minds with time: a comparison of hypothetical and actual reproductive behaviors in parents of children with cystic fibrosis. Pediatrics 2006; 118 e649-e656.

46 Sanderson SC, O'Neill SC, Bastian L, Bepler G, McBride CM: What can interest tell us about uptake of genetic testing? Intention and behavior amongst smokers related to patients with lung cancer. Public Health Genomics 2009; 13: 116-124.

Supplementary Information accompanies this paper on European Journal of Human Genetics website (http://www.nature.com/ejhg) 